\title{
Developing a Model for Strategic Agility in Knowledge-Based Companies using a Mixed Methods Approach
}

\author{
Asma Soltaninezhad ${ }^{1}$ (D), Ali Morovati Sharifabadi ${ }^{1}$ (D), Habib Zare Ahmadabadi ${ }^{1}$ (D), Ahmad Jafarnejad² ID $^{2}$ \\ ${ }^{1}$ Yazd University (Iran \\ ${ }^{2}$ University of Tebran (Iran) \\ a_soltani1969@yahoo.com,_Alimorovati@yazd.ac.ir,Zarehabib@yazd.ac.ir,Jafarnjd@ut.ac.ir
}

Received: January 2020

Accepted: March 2020

\begin{abstract}
:
Purpose: In a global supply chains and complex market environment, companies have to improve performance and gain competitive advantages, thus the need for strategic agility. The purpose of this paper is to demonstrate systematic application of grounded theory to understand strategic agility in knowledge-based companies (KBCs) in Iran and to explain relationships between them.

Methodology: This study uses mixed methods research to explore the determinants of strategic agility in KBCs. This study uses mixed methods approach. Qualitative analysis using "Paradigm model" of grounded theory for data analysis. In Quantitative stage, Structural equation modeling with partial least square is used.

Findings: The results of the first phase of the study revealed that causal conditions affecting strategic agility were organizational and environmental factors. As well, intervening conditions included Facilitating and Deterring role of intrinsic attributes of companies; and contextual conditions encompassed Limiting and Encouraging factors. Moreover, strategies and practices were comprised of Extra-organizational and Intra-organizational practices and consequences of strategic agility were consequences at macro and organizational level. The results of the quantitative study, as the second phase, correspondingly confirmed factors identified at the qualitative phase and demonstrated that the casual conditions explain $79.7 \%$ of the variance in strategic agility, the three independent constructs explain $57.5 \%$ of the variance in strategies, and the strategies explains $55.4 \%$ of the variance of consequences.
\end{abstract}

Research limitations: This study was developed on the basis of opinions of a limited number of individuals which could reduce theoretical generalizability of the results. Another limitation is that the research data are limited to KBCs in Iran.

Value: The results of this study would theoretically complement the body of knowledge about KBCs which can be cited in future research. Furthermore, the mixed methods approach offers a better insight in understanding strategic agility in KBCs vs the use of either a qualitative or quantitative method alone.

Keywords: strategic agility, knowledge-based company, grounded theory, structural equation modeling

\section{To cite this article:}

Soltaninezhad, A., Morovati Sharifabadi, A., Zare Ahmadabadi, H. \& Jafarnejad, A. (2021). Developing a model for strategic agility in knowledge-based companies using a mixed methods approach. Journal of Industrial Engineering and Management, 14(2), 176-198. https://doi.org/10.3926/jiem.3083 


\section{Introduction}

Nowadays, the world is drawn against significant changes and challenges, moving organizations in various directions. Organizations are also operating under circumstances replete with uncertainty, turbulence, dynamism, and hostility which are absolutely not safe and reliable (Bhamra, Dani \& Burnard, 2011). Firms with operations, suppliers and customers located in any part of the world have been forced to seek new ways to manage their operations outside the strict limits of the individual company, and the supply chain has come under increasing scrutiny (Alfalla-Luque, Machuca \& Marin-Garcia, 2018). To deal with such changes, organizations demand approaches enhancing their flexibility and adaptability to recognize market changes, and then reacts appropriately by, for example, moving to different facilities, using different suppliers or outsourcing in changing environments. Accordingly, one of the approaches adopted by organizations to understand changing market trends and needs and to respond quickly to them is agility (Marin-Garcia, Alfalla-Luque \& Machuca, 2018; Perera, Soosay \& Sandhu, 2014). By definition, agility refers to the capability with a reactive nature to change, which focuses on processes and policies within a company and can be used to meet changing conditions (Ganguly, Nilchiani \& Farr, 2009; Ojha, 2008). On the other hand, changing stakeholder needs, increasing global competitions, and growing rates of changes have created conditions such that current routines and therefore the reactive nature of agility by itself can be inadequate (Doz \& Kosonen, 2010; Long, 2000). In this way, a new type of agility is required that not only is beyond adaptation to change and reaction but also enables organizations make changes in their business models and more rapidly seize resulting opportunities for change. This new type of agility, called strategic agility, is a dynamic capability which has been recognized as the key to success in today's changing environment (Al-Azzam, Irtaimeh \& Khaddam, 2017; Castiaux, 2012; Parmigiani, Klassen \& Russo, 2011). Strategic agility is essential in supply chain for both understanding the environment and addressing its demands. Companies working together to deliver required products and services taking advantage of diverse global opportunities and varying expertise and experience from partners in the chain (Mavengere, 2009).

Strategic agility as a very significant concept in the fast-changing business environment has been so far rarely studied in small organizations. Therefore, in such conditions in which even large organizations are not able to survive challenges, efforts need to be made to help small organizations withstand uncertainties and challenges in this environment (Asil, 2019; Bhamra et al., 2011). Strategic agility can also help these companies stay one step ahead of their customers, particularly competitors, and accomplish success (Doz \& Kosonen, 2006; Santala, 2009).

It is noteworthy that small companies as the major sources of income and employment and the driving force in economic development play vital and unquestionable roles in developing countries in terms of promoting social welfare, reducing poverty and injustice, as well as boosting sustainable development. Firms with operations, suppliers and customers located in any part of the world have been forced to seek new ways to manage their operations outside the strict limits of the individual company, and the supply chain has come under increasing scrutiny (Alfalla-Luque et al., 2018). In Iran, upstream documents including policies of the Article 44 of the Constitution, development plans, as well as Iran's 20-Year Vision Document have reflected on knowledge-based economy as one of the most important and influential industries and have further made the development of this sector as a priority in Iran's development plans .

Considering the role of knowledge-based companies (KBCs) in development of a country and given that expanding and strengthening strategic agility capabilities leads to survival and success of these companies in everchanging environments, the purpose of this study is to design a model for strategic agility in KBCs to provide them to put up with the rapidly changing environment and to contribute to their successful performance and consequently economic development in Iran. Since previous research had rarely shed light on strategic agility in KBCs, this study attempted to conduct a mixed methods research to better perceive strategic agility and to develop a comprehensive model for this phenomenon. This paper is organized as follows. Section 2 reviews literature and related studies for strategic agility in KBCs. Section 3 describes the mixed research methodology we used to produce the theoretical model and the survey instrument that tested the model. Section 4 discusses the qualitative research process and presents the research findings. Section 5 sets up the quantitative research model and hypotheses then shows data analysis and research findings. Section 6 and section 7 offer discussions conclusions. 


\section{Literature Review}

\subsection{Strategic Agility}

Strategic agility has emerged as a dynamic and active trend (Doz \& Kosonen, 2010; Weber \& Tarba, 2014). Strategic agility is about companies' capabilities to constantly adapt to changing settings. It also provides the possibility of using opportunities, value creation and satisfaction of customers with high expectations (Arbussa, Bikfalvi \& Marquès, 2017; Qin \& Nembhard, 2010; Tallon \& Pinsonneault, 2011). Strategic agility can provide the basis for sustainable strategic advantage based on unknown things for Competitors (Santala, 2009). Doz et al. have defined strategic agility consisting of three meta-capabilities: strategic sensitivity, Resource fluidity, and leadership unity (Doz \& Kosonen, 2008). Strategic sensitivity is necessary in the supply chain downstream, which is in constant interaction with the customers. The customer taste is ever changing and thus the need for strategic sensitivity to keep in touch with the changes (Mavengere, 2009). Resource fluidity involves the configuration and redeployment of resources timely after consideration of the internal capabilities and external environment requirements (Tallon \& Pinsonneault, 2011). In supply chain strategic response is required by all the partners to enable informed and uniform transformation in responding to the environment demands. However, the partners with the task of product formulation usually SC upstream should have high capacities to respond to required product changes (Mavengere, 2009).

Human resources capabilities and infrastructure and information resources capabilities are the main elements of collective capabilities dimension. Human resources capability is a measure of the ability of the workforce to effectively and efficiently perform their duties. High levels of collective capabilities are required from all the partners in the SC because of the value of these capabilities to sensing and responding dimensions as well as in enhancing collaboration (Mavengere, 2009).

Strategic agility requires the invention of new business models and new sets rather than the renovation of existing products and sets (Wilson \& Doz, 2011). Based on an adaptive organizational culture, strategic agile companies create new ways for change management, restoration of business structure, learning skills and knowledge transfer (Weber \& Tarba, 2014).

Strategic agility challenge is hidden in adaptation of company's strategy to resources of the company, including: capital, human resources, intellectual property, advanced production technologies and IT, knowledge transfer, creating a merger possibility after purchase, coordination mechanisms among multinationals and their subsidiaries, adaptation of leadership style to changing business Environment and readiness for changing ineffective strategic decisions (Combs, Ketchen, David, Ireland \& Webb, 2011; Lewis, Andriopoulos \& Smith, 2014; Nadkarni \& Herrmann, 2010). Besides, the strategic agility challenge in emerging markets is related to the adaptation of strategy and resources of the company to varied and demanded complexities in terms of organization. Thus, today's challenges in the competitive Environment that companies face, make it necessary to understand strategic agility, its theoretical principles, potential components and its implications for the performance of the companies deeply (Weber \& Tarba, 2014). To achieve strategic agility, development of key capabilities required for facilitating renewal and changing business models of organizations is important (Bock, Opsahl, George \& Gann, 2012). For example, human resource management methods can alleviate tensions during organizational transformation (Burgess, Strauss, Currie \& Wood, 2015). Also, a leader who can manage strategic paradoxes can make strategic agility possible (Lewis et al., 2014). Strategic agility can enhance the positive effects of technological capabilities on exploratory innovations (Ahammad, Glaister \& Gomes, 2019). In terms of entrepreneurial cooperation, the social role of entrepreneurship makes cooperation among shareholders a necessity (Zahra \& Wright, 2016). Thus, strategic agility is vital for participants to interact actively with entrepreneurs and create value for different shareholders. Entrepreneurial cooperation needs agile approaches facing partners during passing the lack of confidence (Liu \& Almor, 2016).

\subsection{Related Studies for Strategic Agility in KBCs}

Research by Arbussa et al. (2017) studied the dynamic capabilities fit under strategic agility in terms of an industrial SME that implements business model innovation. Findings show that two meta-capabilities (leadership unity and Resource fluidity) are inherent for SMEs. One of the meta-capabilities (strategic sensitivity) is less inherent in SMEs 
but it is still important. Another important meta-capability is resourcefulness that is necessary for SMEs to be able to overcome limitations resulted from size. Shin, Lee, Kim and Rhim (2015) investigated the strategic agility nature and the role and its effect. They presented a model to study the effects of strategic agility, operational performance, and performance of the company. They also measured the performance of the company in terms of customer retention and financial performance. Santala (2009) examined the justification of strategic agility in a small knowledge intensive business services company tried to identify factors related to them. Findings of this study can be summarized as follows: to discuss on strategic agility of knowledge-based service SMEs in comparison to large companies, other dimensions should be considered in which individual role is the most important dimension in such firms. Challenges related to people's management and motivation in such companies who are most competent and expert should be studied.

As represented in the above literature review, there is no comprehensive framework for strategic agility especially in knowledge-based companies. Most studies on strategic agility have focused on analyzing and identifying the factors and tools for achieving strategic agility. Moreover, none of the existing studies have adopted grounded theory as a methodology to explore strategic agility interactions.

\subsection{The Importance of Strategic Agility for KBCs}

In today's world there are a lot of challenges in global and regional economy alongside particular structural features of these companies that make smaller companies more fragile against rapid Environmental changes. So, they need to adapt to these changes to achieve competitive advantage (Asil, 2019; Gray, 2002; Rant \& Černe, 2017; Woods \& Joyce, 2003). Among small companies, knowledge-based companies are among the ones that need such studies to ensure survival and success. Strategic agility is really important for knowledge-based companies (Doz \& Kosonen, 2008 ). Since strategic agility is the balance point between being agile and being strategic, small companies that are inherently agile need to be more strategic because agility without strategy isn't better than strategy without agility (Long, 2000). In developing countries like Iran, due to inflammatory atmosphere of economy, knowledge-based companies need to improve themselves in terms of strategic agility to be able to deal with Environmental changes and chaos and finally survive.

\section{Research Methodology}

In this study a mixed method approach was used to address the research problem and data analysis is performed in two phases: the qualitative approach in the first phase and the quantitative approach in the second. In the first phase, this study has adopted grounded theory approach. Grounded theory is a methodology for generating theory from the data systematically obtained (Strauss \& Corbin, 1994). The methodology is very useful in deriving knowledge with respect to the context in which it is applied. Since there is limited knowledge on strategic agility of KBCs, this study has used grounded theory method. At the qualitative phase, semi-structured interviews were conducted with academic elites and members of parliament (MPs). In the second phase, the quantitative study is conducted to obtain further empirical support for the theoretical framework developed in Phase 1 and the research model and hypotheses are constructed based on qualitative research findings. Data are then collected through questionnaire surveys, and Partial Least Squares (PLS) is used to analyze the survey data and test the research hypotheses. Research processes in each step are further elaborated in the following explanation.

\section{Qualitative Design and Data Analysis (Phase I)}

This paper employs the Grounded Theory (GT) of the qualitative research method to investigate the strategic agility of KBCs. GT was first proposed by Glaser and Strauss (1967). It helps and guides researchers to keep an open mind to discover unbiased new conceptual models from the emerging patterns in the qualitative data (Glaser \& Strauss, 1967). In other words, GT is a theory construction method that is famous and popular in qualitative research and uses the method of induction to analyze phenomena to discover insights. As researchers provide no theoretical hypothesis before the start of the qualitative research, they derive the concepts and propositions directly from the original data through systematic data collection and analysis and then develop a theory (Tu, 2018). As previous research had not dealt with strategic agility in KBCs through a comprehensive model, GT was selected in the present study to meet past research limitations and to gain an understanding of strategic agility in order to 
develop a multifaceted and process-oriented model for this phenomenon to cover factors related to backgrounds and consequences of strategic agility.

\subsection{Qualitative Data Collection}

At the qualitative phase, semi-structured interviews were conducted with a total number of 14 academic elites and members of parliament (MPs) using purposeful and non-random snowball sampling methods. To this end, the academic elites were selected out of faculty members of universities offering industrial management and strategic management programs and working on research areas such as agility, strategic agility, or KBCs. The MPs were also working as the members of the Committee of Knowledge-Based Economy with a doctorate degree in industrial or strategic management. Accordingly, two individuals had work experience in strategic agility, eight of them had performed studies on agility, and four respondents had worked in KBCs. Data collection continued till the point of "theoretical saturation", i.e. the interviews also continued until new data were collected and no difference was observed compared with previous data. Given the approximately 60-minute time allotted to each interview, the researcher reached saturation after 10 semi-structured interviews but continued them with up to 14 individuals to increase the desirability of the concept.

To verify the validity of topic selection in the qualitative stage, theoretical foundations and research backgrounds associated with strategic agility were investigated. To ensure validity, strategies such as data collection from multiple sources of information, reviewing in the course of coding, constant comparisons in data analysis, and confirmation of research partners were utilized. To calculate the reliability of the qualitative stage using inter-coder agreement method, a PhD student in industrial management was further requested to contribute to the study as a research fellow and to encode three interviews. The percentage of inter-coder agreement as an index for reliability evaluation was obtained using Equation (1) as follows:

$$
\text { Percent agreement }=(\text { number of agreements } \times 2) /(\text { total codes }) \times 100
$$

As can be seen in Table 1, the average inter-coder reliability was determined by $75.1 \%$ using Equation 1 . Given that this reliability value was more than $60 \%$ (Plas, Kvale \& Kvale, 1996), coding reliability was established and it was confirmed that the interviews were endowed with good reliability.

\begin{tabular}{|c|c|c|c|c|}
\hline Interview No & Total codes No & Agreements No & Disagreement No & Reliability of two coders \\
\hline 2 & 39 & 30 & 9 & $76 \%$ \\
\hline 8 & 54 & 22 & 10 & $81 \%$ \\
\hline 12 & 65 & 23 & 19 & $70 \%$ \\
\hline & & & & $75 \%$ \\
\hline
\end{tabular}

Table 1. Inter-coder reliability

\subsection{Qualitative Data Analysis}

Data analysis was done in three stages, i.e. open coding, axial coding and selective coding (Strauss \& Corbin, 1994). The first step of the analysis process was open coding in which various themes were identified from the data. After identification of the themes, axial coding was followed where, these themes were placed under six categories of "paradigm model" suggested by Strauss and Corbin (1994).

\subsubsection{Open Coding}

Open coding is a kind of analysis performed via detailed analysis, naming, and categorization of data. At this step, 286 primary codes were extracted from the main points in the interviews and they were then converted into 41 more abstract concepts and 14 categories were subsequently determined based on their comparison and categorization, explained at axial coding step. An example of open coding is described in Table 2.

At the next step, the extracted codes were refined from open coding and then separated to form coding families. 


\begin{tabular}{|l|l|}
\hline \multicolumn{1}{|c|}{ Concept } & \multicolumn{1}{c|}{ Code } \\
\hline Organizational survival & $\begin{array}{l}\text { Staying relevant in a changing business environment, adaptation to changing environment, } \\
\text { dependency on environment and related changes, failure to compete in markets, organizational } \\
\text { restructuring, flexibility, conflict between company's capabilities and market trends and needs }\end{array}$ \\
\hline $\begin{array}{l}\text { Financial and human } \\
\text { resources constraints }\end{array}$ & $\begin{array}{l}\text { Financial problems, human resources constraints, research and development (R\&D) costs, } \\
\text { individualistic experts, return on invested capital }\end{array}$ \\
\hline $\begin{array}{l}\text { Marketing knowledge } \\
\text { development }\end{array}$ & $\begin{array}{l}\text { Active R\&D, market- and environment-oriented thinking, design of subsystems for environment } \\
\text { and market scanning, knowledge base creation and enrichment, timely and adequate market } \\
\text { knowledge, development of knowledge channels between supply chain members }\end{array}$ \\
\hline $\begin{array}{l}\text { Expanded } \\
\text { organizational } \\
\text { participation and } \\
\text { commitment }\end{array}$ & $\begin{array}{l}\text { Giving freedom of action to employees, attention to employee commitment, designing a } \\
\text { motivational system, employing individuals with different motives and competencies, use of social } \\
\text { capital, participatory decision-making }\end{array}$ \\
\hline
\end{tabular}

Table 2. Examples of open coding

\subsubsection{Axial Coding}

While open coding splits the data into different categories, the axial coding is able to connect their categories and sub-categories according to their characteristics and dimensions. In this study, six categories were identified after examining the concepts and categories. These six categories are: causal conditions, context, intervening conditions, phenomenon, strategies and consequences. With respect to this paper, it comprises: first, the causal conditions leading to strategic agility; second, the context in which strategic agility occurred; third, the intervening conditions either giving rise or restricting strategic agility implement; fourth; the phenomenon of strategic agility in KBCs; fifth, the strategies adopted to implement strategic agility; and sixth, the consequences of strategic agility implementation. "Paradigm model" helps the researcher systematically relate the core phenomenon with the subsidiary categories (Strauss \& Corbin, 1994).

\subsubsection{Causal Conditions}

In this study, the sub-categories of environmental factors affecting need for strategic agility and organizational ones were identified as causal conditions, represented in Table 3.

Based on the interviewees' opinions, increasing complexity and environmental dynamics were among the environmental factors affecting need for strategic agility in KBCs. As stated by one of the interviewees:

"There is a good deal of variation in business environment and many rapid changes are also occurring in the environment, so market makes knowledge-based companies deal with strategic agility."

\begin{tabular}{|l|l|l|}
\hline \multicolumn{1}{|c|}{ Sub-category } & \multicolumn{1}{|c|}{ Concept } & \multicolumn{1}{c|}{ Final code } \\
\hline $\begin{array}{l}\text { Environmental } \\
\text { factors affecting need } \\
\text { for strategic agility }\end{array}$ & Rising competition & $\begin{array}{l}\text { Increasing global competition, expanding competitors, rising } \\
\text { bargaining power in customers and suppliers }\end{array}$ \\
\cline { 2 - 3 } & $\begin{array}{l}\text { Increasing complexity and } \\
\text { environmental dynamics }\end{array}$ & $\begin{array}{l}\text { Predictability of changes, rapid changes in environment and market, } \\
\text { wide variety of businesses }\end{array}$ \\
\hline $\begin{array}{l}\text { Organizational } \\
\text { factors affecting need } \\
\text { for strategic agility }\end{array}$ & $\begin{array}{l}\text { Identifying changing market } \\
\text { trends and needs }\end{array}$ & $\begin{array}{l}\text { Updating based on market trends and needs, identifying trends and } \\
\text { changes in markets }\end{array}$ \\
\cline { 2 - 3 } & $\begin{array}{l}\text { Adaptation to changing } \\
\text { environment }\end{array}$ & $\begin{array}{l}\text { Staying relevant in business environment, ensuring organizational } \\
\text { survival, dependency on environment and related changes }\end{array}$ \\
\hline
\end{tabular}

Table 3. Final codes, Concepts and sub-categories of causal conditions 


\subsubsection{Intervening Conditions}

The intervening conditions in this study included ones presented in Table 4.

From the interviewees' perspectives, the intrinsic attributes of companies could play a significant role in facilitating or deterring fulfillment of strategic agility. Knowledge workers were also taken into consideration as one of the intrinsic attributes of companies in terms of facilitating the implementation of strategic agility. For example, one of the interviewees stated that:

"Employees working in knowledge-based companies are predominantly bighly educated individuals with a tendency to plan and participate in different activities and are experienced enough in scientific issues. On the other hand, these experts are eager to express their opinions, which can be a real challenge for their managers who are sometimes unaware of principles of effective leadership."

\begin{tabular}{|c|c|}
\hline Sub-category & Concept \\
\hline \multirow{2}{*}{$\begin{array}{l}\text { Facilitating role of intrinsic } \\
\text { attributes of companies }\end{array}$} & Knowledge workers \\
\hline & Power to adapt to changing environmental conditions \\
\hline \multirow{3}{*}{$\begin{array}{l}\text { Deterring role of intrinsic } \\
\text { attributes of companies }\end{array}$} & Limited financial and human resources \\
\hline & Weaknesses in managerial expertise \\
\hline & Role of inherent nature of a company \\
\hline
\end{tabular}

Table 4. Concepts and sub-categories of intervening conditions

\subsubsection{Contextual Conditions}

The Contextual conditions in this study included ones presented in Table 5.

According to the interviewees, one of the factors with a limiting role in the implementation of strategic agility was government economy policies. In this respect, an interviewee reiterated that:

"Government economy policies and economic rent helping a company to establish relationships with the government to be more successful is a devastating blow to these companies. Reliance on government economy policies as well as high expectations and false hope for the government can condemn these companies to death."

\begin{tabular}{|l|l|}
\hline \multicolumn{1}{|c|}{ Sub-category } & \multicolumn{1}{c|}{ Concept } \\
\hline \multirow{4}{*}{ Limiting factors } & Reliance on government economy policies \\
\cline { 2 - 2 } & Political uncertainties \\
\cline { 2 - 2 } & Qualities of cultural and educational systems \\
\cline { 2 - 2 } & Weaknesses in marketing and foreign trade \\
\cline { 2 - 2 } & Inadequate business infrastructure \\
\hline \multirow{3}{*}{ Encouraging factors } & Government support policies \\
\cline { 2 - 2 } & Being knowledge-based \\
\cline { 2 - 2 } & Development of information technology infrastructure \\
\hline
\end{tabular}

Table 5. Concepts and sub-categories of contextual conditions

\subsubsection{Core Phenomenon}

Since the main purpose of this study was to present a model of strategic agility, the core phenomenon under consideration was strategic agility. The concepts and categories of this dimension are outlined in Table 6.

Some of the statements made by the interviewees as concepts constituting the core phenomenon were as follows: 
"I think strategic agility means being able to sense and respond to customer-level opportunities, operations, and partners, and also build capabilities that can help in terms of feeling, responding, and learning."

"The first and the most important component of strategic agility can be defined as focusing on the environment and market. In the management team of knowledge-based companies, in which thoughts and perspectives are mostly product-oriented, market- and environment-oriented ones must be also available. The second point is that these companies should design a subsystem that can scan the environment and markets and also establish interactions."

"The focus should not be merely on technology and production. Their resources should be fluid enough and they must make at least possible investments in different areas because they do not yet have a deep understanding of market conditions. These companies are more product-and production-oriented, so they have to be open-minded and seek for more and more elements. Their resources should not be concentrated in one place that can lead to inertia in the company and also its inflexibility."

"Strategic agility means moving forwards based on changes in a way that rates of change in a company are greater than those observed in markets. So, changes are indispensable parts of these companies and the world is also full of changes. These changes must be considered in a long-term plan. Therefore, knowledge-based companies have to operate in line with the most recent science and technology to predict a relatively sustainable future if they want to attain strategic agility."

"Strategic agility in knowledge-based companies means that a company thinks beforehand for us before we try to think and recognizes our trends and needs, that is, moving based on principles of the day and behaving intelligently towards the future."

"Strategic agility means having a vision for both planning and human resources management."

\begin{tabular}{|l|l|}
\hline \multicolumn{1}{|c|}{ Sub-category } & \multicolumn{1}{c|}{ Concepts } \\
\hline \multirow{4}{*}{ Strategic sensitivity } & Strategic foresight \\
\cline { 2 - 2 } & Quick response to changes \\
\cline { 2 - 2 } Leadership unity & Smart market \\
\hline \multirow{2}{*}{ Resourcefulness } & Collective wisdom in decision-making \\
\cline { 2 - 2 } & Management efficiency \\
\hline \multirow{2}{*}{ Resource fluidity } & Innovation in problem-solving \\
\cline { 2 - 2 } & Top-quality employees as a leverage \\
\hline & Perfect capital mobility and use of individuals fitting new initiatives \\
\cline { 2 - 2 } & Flexible database of resources \\
\hline
\end{tabular}

Table 6. Concepts and categories of core phenomenon

\subsubsection{Strategies}

To outline the strategies and practices in the strategic agility model, the concepts and categories of this dimension are presented in Table 7.

According to the interviewees, enhancing communication with supply chain partners to identify product customers, integrating with other KBCs, as well as connecting with science centers encompassed some of the cases in the area of extra-organizational practices that could help overcome problems facing these companies due to resources and employee constraints as well as unfamiliarity with market concepts. For example, an interviewee added that:

"Strategic agility should be a priority in programs and also relationships with upstream and downstream competitors need to be strengthened."

"Such companies have to connect to universities and science centers and make the best use of their knowledge." 


\begin{tabular}{|l|l|}
\hline \multicolumn{1}{|c|}{ Sub-category } & \multicolumn{1}{c}{ Concepts } \\
\hline \multirow{5}{*}{ Extra-organizational practices } & Expanding strategic communication channels \\
\cline { 2 - 3 } & Sharing knowledge with different stakeholders \\
\cline { 2 - 3 } Intra-organizational practices & Enabling support systems to enhance competitiveness of companies \\
\cline { 2 - 3 } & Planning to penetrate into new markets \\
\cline { 2 - 3 } & Developing entrepreneurial culture \\
\hline & Broadening marketing knowledge \\
\cline { 2 - 3 } & Creating a resource allocation process \\
\cline { 2 - 3 } & Making investment in management restructuring as a continuous process \\
\cline { 2 - 3 } & Increasing organizational participation and commitment \\
\cline { 2 - 3 } & Exploiting information technology capacity \\
\hline
\end{tabular}

Table 7. Concepts and sub-categories of strategies

\subsubsection{Consequences}

To identify the consequences of implementing strategic agility in terms of strategies and practices, the concepts and categories of this dimension are illustrated in Table 8.

Examples of what the interviewees said about the consequences of implementing strategic agility were as follows:

"Knowledge-based companies are considered as the competitive edge of a country, and the competitiveness of a country will have a rising trend if they succeed."

"Implementing strategic agility and its results including success and survival of such companies can have outcomes at the national level such as creating top-quality job opportunities and larger organizations in the future."

\begin{tabular}{|l|l|}
\hline \multicolumn{1}{|c|}{ Sub-category } & \multicolumn{1}{c|}{ Concept } \\
\hline \multirow{3}{*}{ Consequences at macro level } & Knowledge economy development \\
\cline { 2 - 2 } & Improvement of business environment \\
\hline \multirow{4}{*}{ Consequences at organizational level } & Continuous restructuring of competitive advantage \\
\cline { 2 - 2 } & Long-term survival \\
\cline { 2 - 2 } & Expanding market share \\
\cline { 2 - 2 } & Profitability and growth \\
\hline
\end{tabular}

Table 8. Concepts and categories of consequences

\subsubsection{Selective Coding}

Open and axial coding can lead to emergence of a set of categories. Therefore, linking such categories to one another can be labeled as selective coding that makes use of the results of previous coding steps and selects the main category and connects it systematically to the other ones. Given the categories identified in this area, the qualitative model of the study is as Figure 1. 


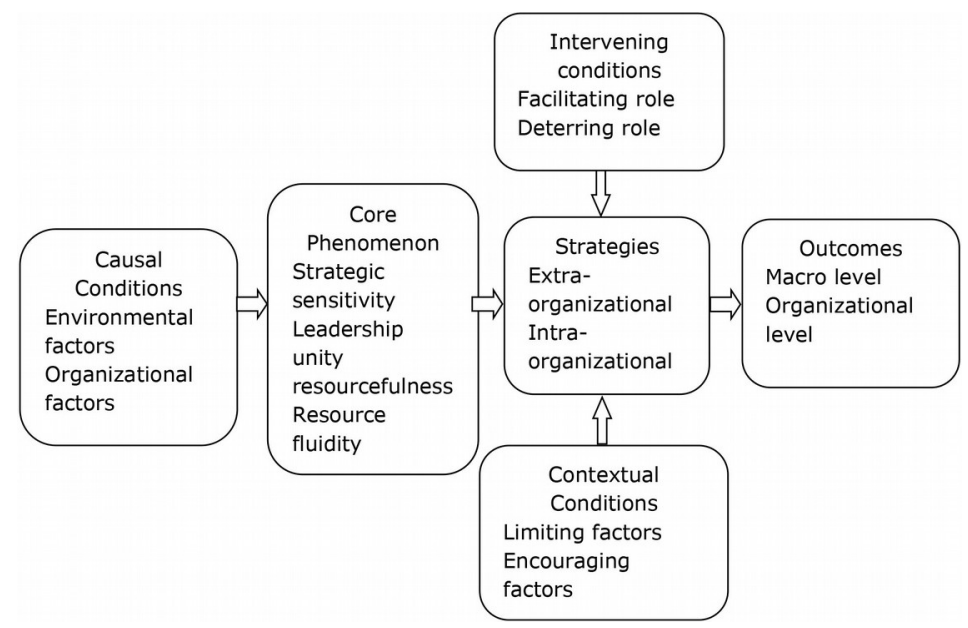

Figure 1. The research model

\section{Quantitative Design and Data Analysis (Phase II)}

\subsection{Hypotheses}

According to the components of the qualitative model in this study (Figure 1), five hypotheses were raised:

Hypothesis 1: Organizational and environmental factors concerning need for strategic agility are effective.

Hypothesis 2: Intrinsic attributes of companies affect strategies derived from strategic agility.

Hypothesis 3: Contextual constraints and incentives affect strategies derived from strategic agility.

Hypothesis 4: There is a positive relationship between strategic agility and resulting strategies.

Hypothesis 5: Intra-organizational and extra-organizational practices resulting from strategic agility are effective in achieving macrolevel and organizational consequences.

\subsection{Data Collection}

As the model was created at the qualitative phase of the study, each measurable code was then transformed into an item to measure it, and the questionnaire was designed. The questionnaire included five constructs and 42 items, and they were measured on a five-point Likert scale ranging from "strongly disagree (1)"to "strongly agree (5)". Afterwards, the questionnaire was assessed in terms of face and content validity. To examine face validity, the designed questionnaire was submitted to a number of professors of management and some items were revised based on their comments. Content validity was also assessed through a comprehensive literature review and the results of the qualitative research were supported. The questionnaire was also distributed among 30 companies as the experimental group to determine its reliability whose Cronbach's alpha coefficient was higher than 0.7 and appropriate, so all the items were used. The Cronbach's alpha values presented in Appendix 1.

The survey subjects of this research questionnaire are managers of KBCs. The statistical population consisted of KBCs at the Science and Technology Park of Tehran University, Iran. This study chose the Science and Technology Park of Tehran University, Iran with 148 firms and invited them to participate in our online or paper-based survey. The sampling method used in this stage was simple random sampling and 96 questionnaires were collected. We obtained 84 valid responses for a response rate of $57 \%$. Table 9 presented the Demographic information of samples. 


\begin{tabular}{|l|l|r|}
\hline \multicolumn{2}{|c|}{ Category } & Frequency \\
\hline \multirow{3}{*}{ Gender } & Male & 72 \\
\cline { 2 - 3 } & Female & 12 \\
\hline \multirow{5}{*}{ Position } & CEO & 61 \\
\cline { 2 - 3 } & Manager & 23 \\
\hline \multirow{5}{*}{ Industry } & ICT software & 36 \\
\cline { 2 - 3 } & Environmental Technologies & 12 \\
\cline { 2 - 3 } & Petrochemical equipment & 11 \\
\cline { 2 - 3 } & Medical and laboratory equipment & 13 \\
\cline { 2 - 3 } & Electrical and Telecommunication Hardware & 12 \\
\hline
\end{tabular}

Table 9. Demographic information of samples

\subsection{Data Analysis}

This study employs the statistical technique of Partial Least Squares (PLS) to perform data analysis and uses SmartPLS software to analyze research data and empirically test the research model and hypothesis. PLS is one of the methods in the variance-based structural equations family (SEM) and for assessing the relationships between constructs, considering the characteristics of model (Marin-Garcia \& Alfalla-Luque, 2019; Villena \& Souto-Pérez, 2016).

The most prominent justifications for using PLS-SEM in some operations management researches are attributed to: nonnormal data; small sample sizes; exploratory or predictive research; and formative and reflectiveindicators (Hadid, Mansouri \& Gallear, 2016). These concepts are discussed below.

1. Unlike the covariance-based SEM, PLS has minimal requirements on data characteristics; it also does not require a multivariate normal data distribution (Hair, Sarstedt, Ringle \& Mena, 2012; Peng \& Lai, 2012). In CBSEM, non-normal data can lead to underestimated standard errors and inflated goodness of-fit statistics (Peng \& Lai, 2012). PLS-SEM is less stringent when working with nonnormal data because the PLS algorithm transforms nonnormal data in accordance with the central limit theorem (Hadid et al., 2016).

2. Sample size is an important consideration in SEM because sample size directly affects the reliability of parameter estimates, model fit, and statistical power (Peng \& Lai, 2012; Shah \& Goldstein, 2006). It has been argued that PLS performs better than traditional CBSEM techniques when dealing with considerably smaller sample sizes because CBSEM might lead to nonconvergence problems and improper solutions in small samples (Henseler, Ringle \& Sarstedt, 2015).

3. the covariance-based SEM is designed for confirmatory model testing, PLS is a component-based SEM that aims for exploratory or predictive research (Kijsanayotin, Pannarunothai \& Speedie, 2009). PLS does offer advantages for exploratory research and where the problems explored are complex and prior theoretical Knowledge is scarce (Henseler et al., 2015).

4. The inclusion of formative and reflective indicators in CBSEMs might cause identification problems, PLS is well suited for both formative and reflective indicators (Hair et al., 2012; Sarstedt, Ringle, Henseler \& Hair, 2014).

Only 84 valid samples were obtained in this study due to limited number of firms participating in this survey. Given the above analysis, the PLS method is considered as a better alternative than covariance-based SEM for this research, because the nature of our study is more exploratory than confirmatory and due to the small sample size and because of lack of normality of data. PLS also is an appropriate alternative to Structural Equation Modeling develop in the Organization and Management (Villena \& Souto-Pérez, 2016), which is another reason for using PLS in this study. 
PLS consists in a sequence of multiple regressions that allows the weights of construct components and paths to be estimated between exogenous and endogenous constructs. PLS is useful for latent constructs and has two components: measurement model and structural model (Errassafi, Abbar \& Benabbou, 2019; J. Marin-Garcia \& Alfalla-Luque, 2019). In the first stage, the measurement model is analyzed to verify the reliability and validity of the instrument; in stage 2, the structural model is evaluated to test the research hypotheses. The first step when constructing analysis models must always consist in explicitly defining the meaning of the constructs to be used from both a theoretical definition perspective and the specification of the items or indicators to be used to measure these constructs or dimensions (Marin-Garcia \& Alfalla-Luque, 2019). This being a reflective construct if the direction of causation runs from the construct to the indicator, and being the Composite construct if the direction of causality runs from the indicator to the construct (Villena \& Souto-Pérez, 2016). Reflective indicators are defined by the conceptual dimension that represents the construct; there should hence be a high correlation between them as indicators attempt to measure the same concept. Composite indicators may represent different aspects relating to the construct. they are not interchangeable with one another and they all contribute a unique aspect to the construct definition (Marin-Garcia \& Alfalla-Luque, 2019; Villena \& Souto-Pérez, 2016).

\subsubsection{Measurement Model Assessment}

To evaluate the measurement model, we follow different steps depending on the nature of the construct's indicators, which we define when specifying the measurement model (Marin-Garcia \& Alfalla-Luque, 2019). In our model, all constructs are reflective, except for the strategic agility that is a Composite construct. For reflective constructs, this study tests item reliability, internal consistency reliability, convergent validity, and discriminant validity. The measurement for item reliability uses factor loadings on the construct. We examined Loadings above 0.708, the Cronbach's Alpha above 0.7, the rho_A above 0.7, the composite reliability above 0.7, and average variance extracted (AVE) above 0.5 (Marin-Garcia \& Alfalla-Luque, 2019). As shown in Table 10, all of the item loadings are greater than 0.708 , indicating a satisfactory factor loading in the survey instrument. The descriptive table and correlations table of all items presented in Appendix 2 and 3.

As detailed in Table 11, the value of Cronbach's $\alpha$ for each construct ranges from 0.709 to 0.845 , which is greater than the cut-off threshold of 0.7. The rho_A and Composite reliabilities all exceed 0.7, which is above the 0.7 minimum thresholds. The average variances extracted (AVE) score for each construct is above the 0.5. Therefore, these results demonstrate that the reflective constructs in our model are reliable and consistent.

\begin{tabular}{|l|l|r|}
\hline \multicolumn{1}{|c|}{ Constructs } & \multicolumn{1}{c|}{ Item } & \multicolumn{1}{c|}{ Loading } \\
\hline \multirow{3}{*}{ Causal Conditions } & Environmental factors & 0.88 \\
\cline { 2 - 3 } & Organizational factors & 0.88 \\
\hline \multirow{3}{*}{ Intervening Conditions } & Facilitating role & 0.799 \\
\cline { 2 - 3 } & Deterring role & 0.942 \\
\hline \multirow{3}{*}{ Contextual Conditions } & Limiting factors & 0.928 \\
\cline { 2 - 3 } Strategies & Encouraging factors & 0.933 \\
\hline \multirow{2}{*}{ Consequences } & Extra-organizational practices & 0.931 \\
\cline { 2 - 3 } & Intra-organizational practices & 0.912 \\
\hline \multirow{2}{*}{ macro level } & 0.912 \\
\cline { 2 - 3 } & organizational level & 0.942 \\
\hline
\end{tabular}

Table 10. Results of item loadings 


\begin{tabular}{|c|c|c|c|c|}
\hline Constructs & Cronbach's Alpha & rho_A & $\begin{array}{c}\text { Composite } \\
\text { Reliability (CR) }\end{array}$ & $\begin{array}{l}\text { Average Variance } \\
\text { Extracted (AVE) }\end{array}$ \\
\hline Causal conditions & 0.709 & 0.709 & 0.873 & 0.774 \\
\hline Strategies & 0.823 & 0.830 & 0.865 & 0.763 \\
\hline Consequences & 0.839 & 0.863 & 0.925 & 0.860 \\
\hline Contextual conditions & 0.845 & 0.846 & 0.928 & 0.866 \\
\hline Intervening conditions & 0.710 & 0.882 & 0.865 & 0.763 \\
\hline
\end{tabular}

Table 11. Construct validity and reliability

\begin{tabular}{|l|r|r|r|r|r|}
\hline \multicolumn{1}{|c|}{ Constructs } & \multicolumn{1}{c|}{$\begin{array}{c}\text { Causal } \\
\text { conditions }\end{array}$} & $\begin{array}{c}\text { Intervening } \\
\text { conditions }\end{array}$ & Strategies & Consequences & $\begin{array}{c}\text { Contextual } \\
\text { conditions }\end{array}$ \\
\hline Causal conditions & 0.880 & & & & \\
\hline Intervening conditions & 0.484 & 0.873 & & & \\
\hline Strategies & 0.453 & 0.791 & 0.921 & 0.927 & \\
\hline Consequences & 0.368 & 0.580 & 0.745 & 0.482 & 0.931 \\
\hline Contextual conditions & 0.520 & 0.709 & 0.762 & & \\
\hline
\end{tabular}

Table 12. Discriminant validity: Fornell-Larcker Criterion

\begin{tabular}{|c|l|r|r|r|}
\hline \multicolumn{1}{c|}{ Construct } & \multicolumn{1}{|c|}{ Indicators } & Weights & Loading & VIF \\
\hline \multirow{4}{*}{ Strategic agility } & Strategic sensitivity & 0.349 & 0.787 & 1.687 \\
\cline { 2 - 5 } & Leadership unity & 0.427 & 0.784 & 1.464 \\
\cline { 2 - 5 } & resourcefulness & 0.100 & 0.616 & 1.569 \\
\cline { 2 - 5 } & Resource fluidity & 0.440 & 0.749 & 1.435 \\
\hline
\end{tabular}

Table 13. Measurement model for composite indicators

In the measurement model for constructs with composite indicators, content validity of the indicators and their conceptual dimension are very important so the weights obtained from the indicators are shown in Table 13. Loadings were positive for all indicators, and the weight of the indicators was greater than zero (Villena \& Souto-Pérez, 2016). The variance inflation factor (VIF) was used to ensure no collinearity occurred. It is recommended that its value must be less than 3 to show absence of collinearity (Marin-Garcia \& Alfalla-Luque, 2019). In our case, all the values obtained were less than 1.7 which ensures that there are no problems of collinearity.

\subsubsection{Structural Model Assessment}

After confirming that the construct measures are reliable and valid, we will evaluate in the next step the assessment of the structural model results. These needs examining the model's predictive capabilities and the model's fit.

Before, we examined the structural model for collinearity through "VIF value". VIF above 3 in the predictor constructs is a critical level of collinearity between construct (Marin-Garcia \& Alfalla-Luque, 2019).Table 14 shows that all VIF values are below 3. 


\begin{tabular}{|l|r|r|r|}
\hline & Strategic agility & Strategies & Consequences \\
\hline Causal conditions & 1.000 & & \\
\hline Strategic agility & & 2.774 & \\
\hline Contextual conditions & & 2.595 & \\
\hline Intervening conditions & & 2.469 & 1.000 \\
\hline Strategies & & & \\
\hline
\end{tabular}

Table 14. Collinearity Statistics (VIF)

Then, $\mathrm{R}^{2}$ and path coefficients $(\beta)$ along with their significance were used for model assessment criteria. A value of the adjusted determination coefficient $\left(\mathrm{R}_{\text {adi }}^{2}\right)$ between 0.1 and 0.25 indicates little explanatory power, it is moderate between 0.25 and 0.45 and very high if it is between 0.5 and 0.75 . If the $\mathrm{R}_{\text {adj }}^{2}$ values exceed 0.8 , it may imply an overfit (Errassafi et al., 2019; Marin-Garcia \& Alfalla-Luque, 2019). Casual conditions explain 79.7\% of the variance in strategic agility, the three independent constructs explain $73.5 \%$ of the variance in strategies, and the strategies explains $55.4 \%$ of the variance of consequences. As the $\mathrm{R}^{2}$ value in this research ranges from 0.55 to 0.79 , indicating satisfactory predicting power of our research model.

In addition, we used $f^{2}$ effect size to evaluate the change in the $\mathrm{R}^{2}$ value when a specified exogenous construct is omitted from the model. The value of $\mathrm{f}^{2}$ of each path can be analyzed, considering as cut values for low, moderate and high $0.02 ; 0.15$ and 0.35 respectively. $f^{2}$ values in our model are medium.

We evaluated the predictive capability of the model by the Stone-Geisser Q2 value by using the blindfolding technique (Hair et al., 2012). When Q2 value is larger than zero, the exogenous constructs have predictive relevance for the endogenous constructs included in the model (Errassafi et al., 2019). Table 5 shows that Q2' values of model are all above 0 .

The path coefficients in Table 16 indicate the strength of the causal relationship between two constructs. The results show that the path coefficients are significant for all constructs. Specifically, causal conditions has a positive effect on Strategic agility in KBCs, thus supporting H1 $(\beta=0.892$, t-value $=55.387)$. Intervening conditions, and contextual conditions are found to be significantly related to strategies, thus supporting $\mathrm{H} 2(\beta=0.390$, $\mathrm{t}$-value $=4.379)$ and $\mathrm{H} 3(\beta=0.277, \mathrm{t}$-value=2.698). Strategic agility has positive influence on strategies, thus supporting $\mathrm{H} 4(\beta=0.280$, $\mathrm{t}$-value $=2.85)$. Finally, strategies also display a significant and positive effect consequences in KBCs $(\beta=0.745$, $\mathrm{t}$-value $=18.36)$, thus $\mathrm{H} 5$ is supported.

\begin{tabular}{|c|l|r|r|r|}
\hline \multicolumn{2}{|c|}{$\mathrm{R}^{2}$} & Strategic agility & Strategies & Consequences \\
\hline \multirow{3}{*}{$f^{2}$} & Causal conditions & 0.797 & 0.575 & 0.554 \\
\cline { 2 - 5 } & Strategic agility & 3.915 & & \\
\cline { 2 - 5 } & Contextual conditions & & 0.107 & \\
\cline { 2 - 5 } & Intervening conditions & & 0.112 & \\
\cline { 2 - 5 } & Strategies & & 0.233 & 1.244 \\
\hline \multirow{2}{*}{$\mathrm{Q}^{2}$} & & & 0.452 \\
\hline
\end{tabular}

Table 15. Assessment and predictive criteria values 


\begin{tabular}{|l|r|r|r|r|r|}
\hline & \multicolumn{1}{|c|}{$\begin{array}{c}\text { Original } \\
\text { Sample }\end{array}$} & $\begin{array}{c}\text { Sample } \\
\text { Mean }\end{array}$ & \multicolumn{1}{c|}{$\begin{array}{c}\text { Standard } \\
\text { Deviation }\end{array}$} & \multicolumn{1}{c|}{ T Statistics } & P Value \\
\hline Casual conditions -> Strategic agility & 0.892 & 0.894 & 0.016 & 55.387 & 0.000 \\
\hline Intervening Conditions -> Strategies & 0.390 & 0.398 & 0.089 & 4.379 & 0.000 \\
\hline Contextual Conditions -> Strategies & 0.277 & 0.269 & 0.103 & 2.698 & 0.007 \\
\hline Strategic agility -> Strategies & 0.280 & 0.279 & 0.098 & 2.858 & 0.004 \\
\hline Strategies -> Consequences & 0.745 & 0.743 & 0.041 & 18.369 & 0.000 \\
\hline
\end{tabular}

Table 16: The PLS results of the structural model

\section{Discussion}

The major contribution of this paper is that it is among the first to examine the issue of Strategic agility in KBCs using mixed research methods. The results of the study show that the qualitative findings in Phase I can be generalized through quantitative research. Thus, the mixed research method of this study provides a more in-depth understanding than a single method approach.

The final results of the fitted model in this study revealed that the causal conditions affecting strategic agility included environmental and organizational factors. In this respect, the environmental factors consisted of increasing competition, complexity, and environmental dynamics which had made companies encounter much more environmental turbulence at higher levels and disrupt their operations. Numerous studies had further underlined need to cope with ambiguous external environment together with complex variations in customer trends and needs by organizations (Idris \& Al-Rubaie, 2013; Ismail, Poolton \& Sharifi, 2011; Lengnick-Hall \& Beck, 2016; Shin et al., 2015). Identifying market was also highlighted as one of the organizational factors affecting need for strategic agility. Understanding customer demands, identifying potential customers, making changes to strategies in line with new market realities, as well as suggesting a new value for emerging markets had been accordingly introduced as realities in today's business environment (Beck \& Lengnick-Hall, 2016; Ismail et al., 2011; Long, 2000; Roth, 1996). Adaptation to changing environment was correspondingly another organizational factor affecting need for strategic agility. So, long-term performance, performance better than competitors, possibility of change in business to respond to market variations, and organizational survival all required flexible and thoughtful responses to an ever-changing environment (Asil, 2019; Di Minin, Frattini, Bianchi, Bortoluzzi \& Piccaluga, 2014; Huy, 2008; Lewis et al., 2014; Shin et al., 2015; Wang \& Ahmed, 2007).

The dimensions of strategic agility in KBCs could be defined in four categories of strategic sensitivity, leadership unity, resourcefulness, and Resource fluidity. Strategic agility was appropriately recognized as a process in which an organization could consciously understand and focus on strategic improvements to identify changes in the environment and also perceive them (Shin et al., 2015). Moreover, it could turn strengths into a leverage and make use of creative problem-solving methods to deal with intrinsic limitations (Arbussa et al., 2017) and then provide the possibility of reducing decision-making time for strategic issues through encouraging, motivating, and preparing human resources and consequently operationalize the changes in strategic programs through redirecting organizational resources (Arbussa et al., 2017; Santala, 2009).

In previous research, concepts such as contextual conditions of the strategic agility model had not been explored or less addressed in a comprehensive manner. One of the important issues in this field was use of technologies by such companies. Experience of advanced technologies, technology-oriented integration, and network communications and integrated information system infrastructures could thus play important roles in fast and accessible mobility of resources towards the best opportunities (Brannen \& Doz, 2012; Doz \& Kosonen, 2006; Idris \& Al-Rubaie, 2013; Roth, 1996; Shin et al., 2015). Another issue was knowledge-based attributes of these companies. Putting much more emphasis on knowledge and identifying it in a more effective and efficient way than that considered by competitors could thus lead to accelerated learning in an organization (Brannen \& Doz, 2012; Doz \& Kosonen, 2006; Kakkar, 2019; Zięba, 2017). One of the most important contextual factors was the impact of political uncertainties and inadequate business infrastructure. Challenging markets in developing countries could also impede many investments due to high costs and limited financial resources (Hemmati, Feiz, Jalilvand \& 
Kholghi, 2016; Ismail et al., 2011). Moreover, government support for small companies in developing countries could result in quick decision-making and increased risk-taking investment (Shin et al., 2015).

In terms of intervening conditions, the intrinsic attributes of these companies could have both a facilitating and a deterring role. Employees' skills, creativity, innovation, and entrepreneurial skills were accordingly a key element in value creation and business sustainability of a company operating in an increasingly dynamic global environment (Ananthram \& Nankervis, 2013; Roth, 1996). Furthermore, it could enhance ability to communicate quickly with customers and partners, to gather information, to learn from surrounding environment, to share information, and to respond to changing environmental conditions (Hemmati et al., 2016; Ismail et al., 2011; Shin et al., 2015). On the other hand, lack of managerial expertise and managers' assumptions about how to organize work, how to share activities, and how to determine strategies could have effects on diversification of valuable resources and inability to make changes (Ananthram \& Nankervis, 2013; Kakkar, 2019; Tikkanen, 2014). Besides, company size and its limited resources could be assumed as a challenge to effective confrontation with stresses and problems as well as accountability process and consequently weaken such organizations (Ismail et al., 2011).

To fulfill the consequences of implementing strategic agility, several strategies needed to be adopted. Strategies and practices contributing to companies can be thus defined in two categories of intra-organizational and extra-organizational practices. For any organization operating in challenging markets such as those in developing countries, it was imperative to interact with partners, suppliers, and customers to collect information and learn from the surrounding environment. Learning more from industries, customers, and competitors, interactions with the surrounding environment, partners, suppliers, customers, etc. could thus help obtain knowledge resources and achieve organizational goals (Hemmati et al., 2016; Shin et al., 2015). Using techniques such as mergers or acquisitions as well as benefiting other companies' services to increase company outputs and expanding its financial scale were also some of the ways to manage business developments (Santala, 2009). Motivation, development of competencies and in other words leveraging strengths in small companies were a way of overcoming some of the intrinsic limitations facing these organizations (Arbussa et al., 2017; Roth, 1996). Besides, senior executives of such companies could play an important role in building shared understanding, giving employees freedom of action, involving employees in decision-making process, and taking different perspectives into account (Kakkar, 2019; Santala, 2009) that are required to enhance organizational learning and to empower employees through creating more flexible working conditions (Asil, 2019; Roth, 1996; Shin et al., 2015).

Finally, in terms of consequences, expected results and consequences of the strategic agility model were taken into consideration. The expected consequences resulting from implementation of processes as well as strategies and practices of strategic agility model in KBCs could be thus placed at macro and organizational levels. Developing knowledge economy and improving business environment were also concepts falling under macro-level consequences. Accordingly, companies armed with strategic agility could make use of most emerging opportunities, ultimately leading to wealth creation for companies and economic growth for countries (Hemmati et al., 2016; Lungu, 2018). Giving strategic responses to economic volatility, strategic agility could thus increase economic value creation (Di Minin et al., 2014; Ilan, Melih \& Amir, 2017). Another outcome of implementing the strategic agility model was achieving results at organizational level. Continuous refinement of competitive advantage and long-term survival were thus concepts assigned to this category. Operational efficiency improvement and better performance, increased ability to face significant risks, and ability to provide flexible and thoughtful responses to the ever-changing environment, in short, maximizing strengths and providing what is needed for survival of an organization could all depend on strategic agility (Idris \& Al-Rubaie, 2013; Ismail et al., 2011; Lewis et al., 2014; Lungu, 2018). Strategic agility could also play a role in competitiveness of companies at organizational level and lead to success in emerging markets and recreate competitive advantage (Ananthram \& Nankervis, 2013; Fourné, 2012).

Strategic agility models in different research studies contained specific factors and had been designed to meet different needs. With regard to the role of KBCs and the importance of knowledge economy, the strategic agility model for KBCs in this study had similarities and differences with other models in the related literature. One of the differences was that most research on strategic agility had been focused on large organizations and there was not much research on small- and medium-sized companies; as a result, capabilities such as resourcefulness as a way to 
overcome problems facing such companies had been overlooked in strategic agility models designed for large organizations. The present strategic agility model for KBCs, like other ones in previous research, had concentrated on strategic sensitivity, Resource fluidity, and collective commitment although there was a need to consider specific requirements and capabilities of these companies in practice. In addition, these issues could be generalized, as compared with previous research reflecting individually on agile or strategic characteristics. The strategic agility model presented in this study focused on these two areas simultaneously, which can be functional and contributing for small companies.

\section{Conclusion}

The purpose of the present study was to develop a multifaceted, comprehensive, and process-oriented model for strategic agility in KBCs at the Science and Technology Park of Tehran University, Iran, with respect to factors related to backgrounds and consequences of strategic agility. Since previous research had rarely reflected on KBCs, the present study attempted to firstly obtain an understanding of the given phenomenon through qualitative research, and then to quantify the model obtained from the qualitative phase.

The results of this research also have significant managerial and practical implications. Based on the developed model and its dimensions, KBCs manages were recommended to: 1) Enhance causal conditions before using this strategic agility model; so, strengthening relationships with partners, suppliers, and customers to identify competitors, customer demands, and constant market observation are among the necessities of strategic agility. 2) Ensure contextual conditions and requirements for strategic agility in companies since improving infrastructure to use network communications and integrated information systems is one of the most important obligations in this area. 3) Consider all components of strategic agility model including strategic sensitivity, collective commitment, resourcefulness, and Resource fluidity. It should be noted that strategic sensitivity should not be neglected because of the specific circumstances of these companies, playing a vital role in successful implementation of this strategic agility model. 4) Pay attention to intervening conditions such as role of managers and employees, inherent nature of companies, and resource constraints. Networking and cohesion as well as attention to management and employee empowerment are also effective strategies in this domain. 5) Persist and make efforts in case of implementing the strategic agility model, so that they can benefit from competitive advantage of their company as well as economic growth in their country.

A major limitation of this study is the small sample size, which affects the parameter estimates of the research model. Another limitation is that the research data are limited to KBCs at the Science and Technology Park of Tehran University, Iran, indicating a potential culture or regional bias. Therefore, future research is encouraged to collect a larger sample for the quantitative study and also to acquire research data from different industry sectors. By testing the proposed model in other geographies or different industrial sectors, the findings herein can be further validated.

\section{Declaration of Conflicting Interests}

The authors declared no potential conflicts of interest with respect to the research, authorship, and/or publication of this article.

\section{Funding}

The authors received no financial support for the research, authorship, and/or publication of this article.

\section{References}

Ahammad, M.F., Glaister, K.W., \& Gomes, E. (2019). Strategic agility and human resource management. Human Resource Management Review, 100700. https://doi.org/10.1016/j.hrmr.2019.100700

Al-Azzam, Z.F., Irtaimeh, H.J., \& Khaddam, A.A.H. (2017). Examining the Mediating Effect of Strategic Agility in the Relationship between Intellectual Capital and Organizational Excellence in Jordan Service Sector. Journal of Business, 6(1), 7-15. https://scholar.google.com/scholar?cluster $=16917525703465001493 \& \mathrm{hl}=\mathrm{en} \&$ as $\operatorname{sdt}=0,5$ 
Alfalla-Luque, R., Machuca, J.A., \& Marin-Garcia, J.A. (2018). Triple-A and competitive advantage in supply chains: Empirical research in developed countries. International Journal of Production Economics, 203, 48-61. https://doi.org/10.1016/j.ijpe.2018.05.020

Ananthram, S., \& Nankervis, A. (2013). Strategic agility and the role of HR as a strategic business partner: an I ndian perspective. Asia Pacific Journal of Human Resources, 51(4), 454-470. https://doi.org/10.1111/1744-7941.12004

Arbussa, A., Bikfalvi, A., \& Marquès, P. (2017). Strategic agility-driven business model renewal: the case of an SME. Management Decision, 55(2), 271-293. https://doi.org/10.1108/MD-05-2016-0355 http://hdl.handle.net/10256/15504

Asil, A. (2019). Design and Implementation of Strategic Agility Evaluation Model with Structural Equation Modelling Approach. Academy of Strategic Management Journal. https://scholar.google.com/scholar? $\underline{\text { cluster }=13822010453816735651 \& \text { hl }=\text { en\&as } \mathrm{sdt}=0,5}$

Beck, T.E., \& Lengnick-Hall, C.A. (2016). Resilience capacity and strategic agility: Prerequisites for thriving in a dynamic environment Resilience Engineering Perspectives, 2, 61-92. CRC Press. https://doi.org/10.1201/9781315244389

Bhamra, R., Dani, S., \& Burnard, K. (2011). Resilience: The Concept, a Literature Review and Future Directions. International Journal of Production Research, 49(18), 5375-5393. https://doi.org/10.1080/00207543.2011.563826

Bock, A.J., Opsahl, T., George, G., \& Gann, D.M. (2012). The effects of culture and structure on strategic flexibility during business model innovation. Journal of Management Studies, 49(2), 279-305. https://doi.org/10.1111/j.1467-6486.2011.01030.x

Brannen, M.Y., \& Doz, Y.L. (2012). Corporate Languages and Strategic Agility: Trapped in Your Jargon or Lost in Translation? California Management Review, 54(3), 77-97. https://doi.org/10.1525/cmr.2012.54.3.77

Burgess, N., Strauss, K., Currie, G., \& Wood, G. (2015). Organizational ambidexterity and the hybrid middle manager: The case of patient safety in UK hospitals. Human Resource Management, 54(S1), s87-s109. https://doi.org/10.1002/hrm.21725

Castiaux, A. (2012). Developing dynamic capabilities to meet sustainable development challenges, International Journal of Innovation Management, 16(06), 1240013. https://doi.org/10.1142/\$1363919612400130

Combs, J.G., Ketchen, J., David J, Ireland, R.D., \& Webb, J.W. (2011). The role of resource flexibility in leveraging strategic resources. Journal of Management Studies, 48(5), 1098-1125. https://doi.org/10.1111/j.1467-6486.2009.00912.x

Di Minin, A., Frattini, F., Bianchi, M., Bortoluzzi, G., \& Piccaluga, A. (2014). Udinese Calcio soccer club as a talents factory: Strategic agility, diverging objectives, and resource constraints. European Management Journal, 32(2), 319-336. https://doi.org/10.1016/j.emj.2013.04.001

Doz, Y.L., \& Kosonen, M. (2006). Fostering Strategic Agility: In Search for Renewed Growth. CKIR workshop. http://agilityconsulting.com/resources/SAI/INSEADAgility1.pdf

Doz, Y.L., \& Kosonen, M. (2010). Embedding strategic agility: A leadership agenda for accelerating business model renewal. Long range planning, 43(2-3), 370-382. https://doi.org/10.1016/j.lrp.2009.07.006

Errassafi, M., Abbar, H., \& Benabbou, Z. (2019). The mediating effect of internal integration on the relationship between supply chain integration and operational performance: Evidence from Moroccan manufacturing companies. Journal of Industrial Engineering and Management, 12(2), 254-273. https://doi.org/10.3926/jiem.2794

Fourné, S. (2012). Strategic agility: An emerging markets perspective. Paper presented at the Technology Management Conference (ITMC), 2012 IEEE International. https:/ /dx.doi.org/10.1109/ITMC.2012.6306384

Ganguly, A., Nilchiani, R., \& Farr, J.V. (2009). Evaluating agility in corporate enterprises. International Journal of Production Economics, 118(2), 410-423. https://doi.org/10.1016/j.ijpe.2008.12.009

Glaser, B.G., \& Strauss, A.L. (1967). The constant comparative method of qualitative analysis. The discovery of grounded theory: Strategies for qualitative research, 101, 158. https://www.jstor.org/stable/798843 
Gray, C. (2002). Entrepreneurship, resistance to change and growth in small firms. Journal of small business and enterprise development, 9(1), 61-72. https://doi.org/10.1108/14626000210419491

Hadid, W., Mansouri, S.A., \& Gallear, D. (2016). Is lean service promising? A socio-technical perspective. International Journal of Operations \& Production Management. https://doi.org/10.1108/IJOPM-01-2015-0008

Hair, J.F., Sarstedt, M., Ringle, C.M., \& Mena, J.A. (2012). An assessment of the use of partial least squares structural equation modeling in marketing research. Journal of the academy of marketing science, 40(3), 414-433. https://doi.org/ 10.1007/s11747-011-0261-6

Hemmati, M., Feiz, D., Jalilvand, M.R., \& Kholghi, I. (2016). Development of fuzzy two-stage DEA model for competitive advantage based on RBV and strategic agility as a dynamic capability. Journal of Modelling in Management, 11(1), 288-308. https://doi.org/10.1108/JM2-12-2013-0067

Henseler, J., Ringle, C.M., \& Sarstedt, M. (2015). A new criterion for assessing discriminant validity in variance-based structural equation modeling. Journal of the academy of marketing science, 43(1), 115-135. https://doi.org/10.1007/s11747-014-0403-8

Huy, Q. (2008). How contrasting emotions can enhance strategic agility. https://scholar.google.com/scholar? cluster $=7145081079014105007 \& h l=$ en\&as_sdt $=0,5$

Idris, W.M.S., \& Al-Rubaie, M.T.K. (2013). Examining the impact of strategic learning on strategic agility. Journal of Management and Strategy, 4(2), 70. https://scholar.google.com/scholar? cluster $=16341779971813489064 \& \mathrm{hl}=$ en\&as $\mathrm{sdt}=0,5$

Ilan, A., Melih, M., \& Amir, S. (2017). Strategic agility explanations for managing franchising expansion during economic cycles. Competitiveness Review, 27(2), 113-131. https://doi.org/10.1108/CR-04-2016-0022

Ismail, H.S., Poolton, J., \& Sharifi, H. (2011). The role of agile strategic capabilities in achieving resilience in manufacturing-based small companies. International Journal of Production Research, 49(18), 5469-5487. https://doi.org/10.1080/00207543.2011.563833

Kakkar, S. (2019). Leader-member exchange and employee resilience: the mediating role of regulatory focus. Management Research Review, 42(9), 1062-1075. https:/ / doi.org/10.1108/MRR-03-2018-0116

Kijsanayotin, B., Pannarunothai, S., \& Speedie, S.M. (2009). Factors influencing health information technology adoption in Thailand's community health centers: Applying the UTAUT model. International Journal of Medical Informatics, 78(6), 404-416. https://doi.org/10.1016/j.ijmedinf.2008.12.005

Lengnick-Hall, C.A., \& Beck, T.E. (2016). Resilience capacity and strategic agility: Prerequisites for thriving in a dynamic environment Resilience Engineering Perspectives, 2, 61-92. CRC Press. https://doi.org/10.1201/9781315244389

Lewis, M.W., Andriopoulos, C., \& Smith, W.K. (2014). Paradoxical leadership to enable strategic agility. California Management Review, 56(3), 58-77. https://doi.org/10.1525/cmr.2014.56.3.58

Liu, Y., \& Almor, T. (2016). How culture influences the way entrepreneurs deal with uncertainty in interorganizational relationships: The case of returnee versus local entrepreneurs in China. International Business Review, 25(1), 4-14. https://doi.org/10.1016/j.ibusrev.2014.11.002

Long, C. (2000). Measuring your strategic agility. Consulting to Management, 11(3), 25. https://scholar.google.com/

Lungu, M.F. (2018). Achieving strategic agility through business model innovation. The case of telecom industry. Paper presented at the Proceedings of the International Conference on Business Excellence. https://doi.org/10.2478/picbe-20180050

Marin-Garcia, J., \& Alfalla-Luque, R. (2019). Key issues on Partial Least Squares (PLS) in operations management research: A guide to submissions. Journal of Industrial Engineering and Management, 12(2), 219-240.

https://doi.org/10.3926/jiem.2944 
Marin-Garcia, J.A., Alfalla-Luque, R., \& Machuca, J.A. (2018). A Triple-A supply chain measurement model: validation and analysis. International Journal of Physical Distribution \& Logistics Management. https://doi.org/10.1108/IJPDLM-06-2018-0233

Mavengere, N. (2009). Strategic agility of supply chains. Network, 6(3), 4. https://doi.org/10.1504/IJASM.2013.052209

Nadkarni, S., \& Herrmann, P. (2010). CEO personality, strategic flexibility, and firm performance: The case of the Indian business process outsourcing industry. Academy of Management Journal, 53(5), 1050-1073. https://doi.org/10.5465/amj.2010.54533196

Ojha, D. (2008). Impact of strategic agility on competitive capabilities and financial performance. Clemson University. https://scholar.google.com/

Parmigiani, A., Klassen, R.D., \& Russo, M.V. (2011). Efficiency meets accountability: Performance implications of supply chain configuration, control, and capabilities. Journal of operations management, 29(3), 212-223. https://doi.org/10.1016/j.jom.2011.01.001

Peng, D.X., \& Lai, F. (2012). Using partial least squares in operations management research: A practical guideline and summary of past research. Journal of operations management, 30(6), 467-480.

https://doi.org/10.1016/j.jom.2012.06.002

Perera, S., Soosay C., Sandhu, S. (2014). Does agility foster sustainability: development of a framework from a supply chain perspective. 12th ANZAM Operations, Supply Chain and Services Management Symposium. https://scholar.google.com/

Plas, J.M., Kvale, S., \& KVALE, S.A. (1996). Interviews: An introduction to qualitative research interviewing: Sage. https://scholar.google.com/

Rant, M.B., \& Černe, S.K. (2017). How to Successfully Internationalize SMEs from the CEE Region: The Role of Strategies of Differentiation and Education. Journal of Management and Business Administration. Central Europe, 25(4), 2-27. https://doi.org/10.7206/jmba.ce.2450-7814.205

Roth, A.V. (1996). Achieving strategic agility through economies of knowledge. Planning Review, 24(2), $30-36$. https://doi.org/10.1108/eb054550

Santala, M. (Producer). (2009). Strategic agility in a small knowledge intensive business services company: Case Swot Consulting. https://scholar.google.com/

Sarstedt, M., Ringle, C. M., Henseler, J., \& Hair, J. F. (2014). On the emancipation of PLS-SEM: A commentary on Rigdon (2012). Long range planning, 47(3), 154-160. https://doi.org/10.1016/j.lrp.2014.02.007

Shah, R., \& Goldstein, S.M. (2006). Use of structural equation modeling in operations management research: Looking back and forward. Journal of operations management, 24(2), 148-169. https://doi.org/10.1016/j.jom.2005.05.001

Shin, H., Lee, J.-N., Kim, D., \& Rhim, H. (2015). Strategic agility of Korean small and medium enterprises and its influence on operational and firm performance. International Journal of Production Economics, 168, 181-196. https://doi.org/10.1016/j.ijpe.2015.06.015

Strauss, A., \& Corbin, J. (1994). Grounded theory methodology. Handbook of qualitative research, 17, $273-285$. https://scholar.google.com/

Tallon, P.P., \& Pinsonneault, A. (2011). Competing perspectives on the link between strategic information technology alignment and organizational agility: insights from a mediation model. Mis Quarterly, 463-486. https://scholar.google.com/

Tikkanen, J. (2014). Dynamic capability influence on Strategic agility: a case study in energy conservation industry. Master Science in Economics and Business Administration. Oulu Business School: University of Oulu. http://jultika.oulu.fi/files/nbnfioulu-201405211434.pdf 
Tu, M. (2018). An exploratory study of Internet of Things (IoT) adoption intention in logistics and supply chain management: A mixed research approach. The International Journal of Logistics Management, 29(1), 131-151. https://doi.org/10.1108/IJLM-11-2016-0274

Villena, F., \& Souto-Pérez, J.E. (2016). Sustainability, innovative orientation and export performance of manufacturing SMEs: An empirical analysis of the mediating role of corporate image. Journal of Industrial Engineering and Management (IIEM), 9(1), 35-58. http://hdl.handle.net/10419/188761

Wang, C.L., \& Ahmed, P.K. (2007). Dynamic capabilities: A review and research agenda. International journal of management reviews, 9(1), 31-51. https://doi.org/10.1111/j.1468-2370.2007.00201.x

Weber, Y., \& Tarba, S.Y. (2014). Strategic agility: A state of the art introduction to the special section on strategic agility. California Management Review, 56(3), 5-12. https://doi.org/10.1525/cmr.2014.56.3.5

Wilson, K., \& Doz, Y.L. (2011). Agile innovation: A footprint balancing distance and immersion. California Management Review, 53(2), 6-26. https://doi.org/10.1525/cmr.2011.53.2.6

Woods, A., \& Joyce, P. (2003). Owner-managers and the practice of strategic management. International Small Business Journal, 21(2), 181-195. https://doi.org/10.1177/0266242603021002003

Burgess, N., Strauss, K., Currie, G., \& Wood, G. (2015). Organizational ambidexterity and the hybrid middle manager: The case of patient safety in UK hospitals. Human Resource Management, 54(S1), s87-s109. doi: https://doi.org/10.1002/hrm.21725

Combs, J. G., Ketchen, J., David J, Ireland, R. D., \& Webb, J. W. (2011). The role of resource flexibility in leveraging strategic resources. Journal of Management Studies, 48(5), 1098-1125. doi:https://doi.org/10.1111/j.14676486.2009.00912.x

Errassafi, M., Abbar, H., \& Benabbou, Z. (2019). The mediating effect of internal integration on the relationship between supply chain integration and operational performance: Evidence from Moroccan manufacturing companies. Journal of Industrial Engineering and Management, 12(2), 254-273. doi:DOI: http://dx.doi.org/10.3926/jiem.2794

Glaser, B. G., \& Strauss, A. L. (1967). The constant comparative method of qualitative analysis. The discovery of grounded theory: Strategies for qualitative research, 101, 158. https://www.jstor.org/stable/798843

Gray, C. (2002). Entrepreneurship, resistance to change and growth in small firms. Journal of small business and enterprise development, 9(1), 61-72. doi:https://doi.org/10.1108/14626000210419491

Liu, Y., \& Almor, T. (2016). How culture influences the way entrepreneurs deal with uncertainty in interorganizational relationships: The case of returnee versus local entrepreneurs in China. International Business Review, 25(1), 4-14. doi: https://doi.org/10.1016/j.ibusrev.2014.11.002

Nadkarni, S., \& Herrmann, P. (2010). CEO personality, strategic flexibility, and firm performance: The case of the Indian business process outsourcing industry. Academy of Management Journal, 53(5), 1050-1073. doi:https://doi.org/10.5465/amj.2010.54533196

Rant, M. B., \& Černe, S. K. (2017). How to Successfully Internationalize SMEs from the CEE Region: The Role of Strategies of Differentiation and Education. Journal of Management and Business Administration. Central Europe, 25(4), 2-27. doi:http://dx.doi.org/10.7206/jmba.ce.2450-7814.205

Tu, M. (2018). An exploratory study of Internet of Things (IoT) adoption intention in logistics and supply chain management: A mixed research approach. The International Journal of Logistics Management, 29(1), $131-151$. doi: https://doi.org/10.1108/IJLM-11-2016-0274

Weber, Y., \& Tarba, S. Y. (2014). Strategic agility: A state of the art introduction to the special section on strategic agility. California Management Review, 56(3), 5-12. doi:https://doi.org/10.1525/cmr.2014.56.3.5

Wilson, K., \& Doz, Y. L. (2011). Agile innovation: a footprint balancing distance and immersion. California Management Review, 53(2), 6-26. doi:https://doi.org/10.1525/cmr.2011.53.2.6 
Woods, A., \& Joyce, P. (2003). Owner-managers and the practice of strategic management. International Small Business Journal, 21(2), 181-195. https://doi.org/10.1177/0266242603021002003

Zahra, S.A., \& Wright, M. (2016). Understanding the social role of entrepreneurship. Journal of Management Studies, 53(4), 610-629. https://doi.org/10.1111/joms.12149

Zięba, M. (2017). Knowledge safety-Insights from the SME sector. Journal of Management and Business Administration, 25(3), 78-96. https://doi.org/10.7206/jmba.ce.2450-7814.203

\section{Appendix 1. Cronbach's Alpha Coefficient}

\begin{tabular}{|l|r|}
\hline \multicolumn{1}{|c|}{ Constructs } & Cronbach's alpha coefficient \\
\hline Causal Conditions & 0.835 \\
\hline Intervening Conditions & 0.775 \\
\hline Contextual Conditions & 0.877 \\
\hline Strategic agility & 0.833 \\
\hline Strategies & 0.796 \\
\hline Consequences & 0.717 \\
\hline
\end{tabular}

\section{Appendix 2. Descriptive Table}

\begin{tabular}{|l|r|r|r|r|r|r|}
\hline \multicolumn{1}{|c|}{ Indicator } & Mean & Min & Max & $\begin{array}{c}\text { Standard } \\
\text { deviation }\end{array}$ & $\begin{array}{c}\text { Excess } \\
\text { kutosis }\end{array}$ & Skewness \\
\hline Environmental & 2.339 & 1 & 5 & 1.058 & -0.801 & 0.287 \\
\hline Organization & 3.190 & 1 & 5 & 1.026 & -0.409 & -0.335 \\
\hline Facilitating & 2.561 & 1 & 5 & 0.831 & 0.184 & 0.259 \\
\hline deterring & 3.142 & 1 & 5 & 1.019 & -0.645 & -0.290 \\
\hline Limiting & 3.248 & 1 & 5 & 0.926 & 0.141 & -0.368 \\
\hline Encouraging & 3.504 & 1 & 5 & 0.909 & 0.633 & -0.863 \\
\hline Strategic Sensivity & 2.339 & 1 & 5 & 1.058 & -0.801 & 0.287 \\
\hline Leadership Unity & 3.190 & 1 & 5 & 1.026 & -0.409 & -0.335 \\
\hline Resourcefulness & 2.779 & 1 & 5 & 0.875 & -0.022 & -0.064 \\
\hline Resource fluidity & 3.364 & 1 & 5 & 0.911 & 0.167 & -0.592 \\
\hline Etra organizational & 2.988 & 1 & 5 & 1.003 & -0.451 & -0.126 \\
\hline Intra organizational & 3.364 & 1 & 5 & 0.911 & 0.167 & -0.592 \\
\hline Macro level & 2.613 & 1 & 5 & 0.925 & -0.019 & -0.739 \\
\hline Organizational level & 2.939 & 1 & 5 & 1.042 & 0.243 \\
\hline
\end{tabular}




\section{Appendix 3. Correlation Table}

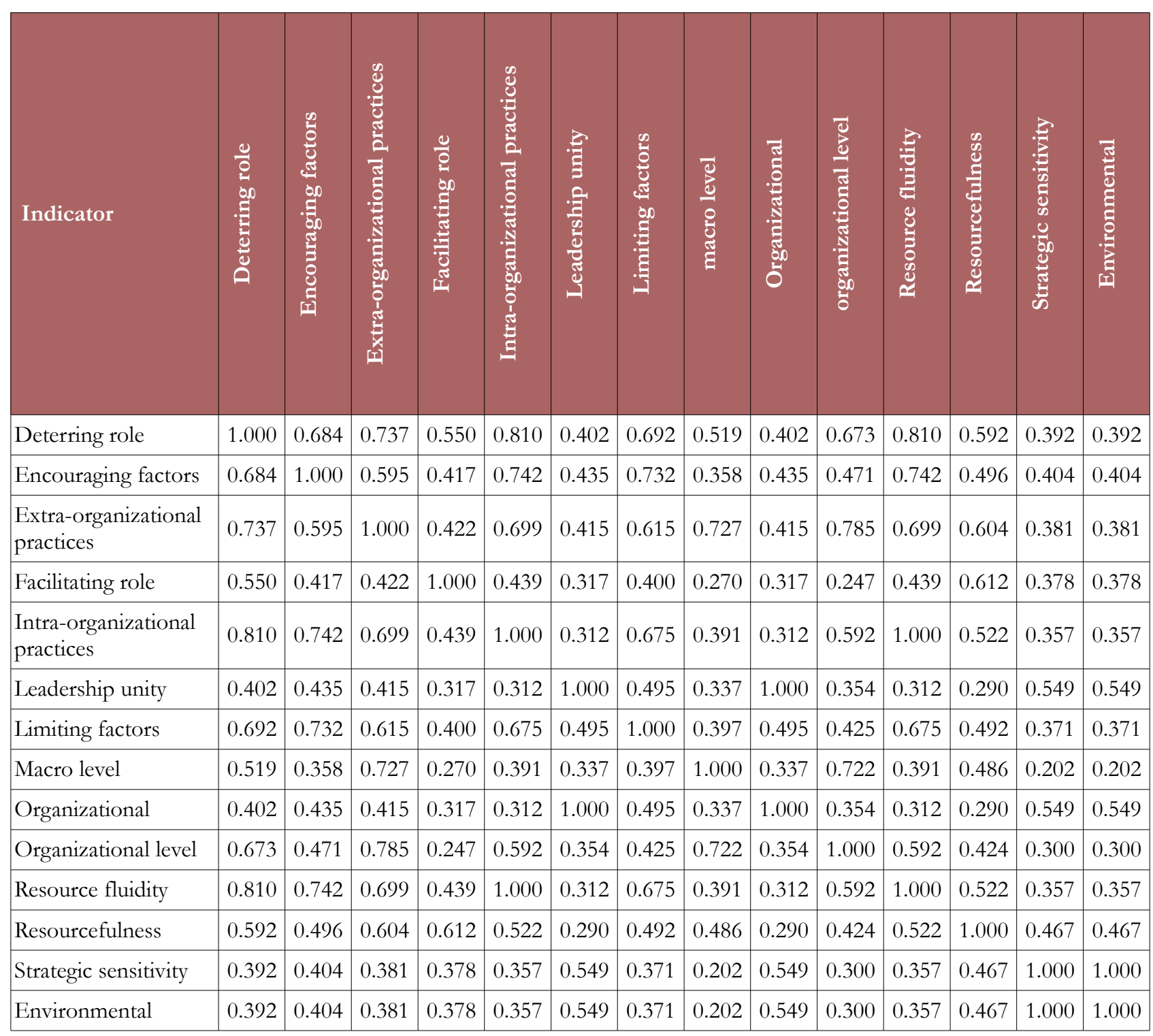

Journal of Industrial Engineering and Management, 2021 (www.jiem.org)

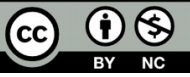

Article's contents are provided on an Attribution-Non Commercial 4.0 Creative commons International License. Readers are allowed to copy, distribute and communicate article's contents, provided the author's and Journal of Industrial Engineering and Management's names are included. It must not be used for commercial purposes. To see the complete license contents, please visit https://creativecommons.org/licenses/by-nc/4.0/. 